\title{
Determination of coefficient of performance of mechanical vapour recompression heat pump
}

\author{
Slav Valchev ${ }^{1 *}$, Nenko Nenov ${ }^{1}$ and Vasil Georgiev ${ }^{1}$ \\ ${ }^{1}$ University of Food Technologies, Plovdiv, Bulgaria, Department of Heat Engineering, 26 Maritza \\ Blvd. BG-4002 Plovdiv, Bulgaria
}

\begin{abstract}
Mechanical vapour recompression heat pump systems are widely used in the industry - in evaporator and distillation installations, in seawater desalination and industrial wastewater treatment plants. The estimation of the energy efficiency level of this type of system is based on values of two basic parameters: specific energy consumption for production of $1 \mathrm{~kg}$ clean water (condensate) and actual coefficient of performance of heat pump system. The object of study is experimental determination of value of actual coefficient of performance of mechanical vapour recompression heat pump system for wastewater treatment. A mathematical regression equation between the actual coefficient of performance $\mu$ and two significant factors - temperature of secondary water vapour $t_{\mathrm{sv}}$ and compression ratio of water vapour in mechanical compressor of heat pump system $\sigma$ is received. The analysis show that actual coefficient of performance $\mu$ highly depends of value of compression ratio $\sigma$ and less depends of values of temperature of secondary vapour $\mathrm{t}_{\mathrm{sv}}$. It conclude that MVR heat pump system, in order to operate with high values of the actual coefficient of performance should be working to high values of temperature of secondary vapour and low values of compression ratio of water vapour in mechanical compressor.
\end{abstract}

\section{Introduction}

In process of wastewater treatment, mechanical vapour recompression (MVR) heat pump system separates wastewater flow into two flows - clean water (condensate) and concentrate sludge with high values of organic dry matters. A condensate with high temperature can be reused in various industrial processes, where a heat or clean water is needed. MVR heat pump system increases the pressure of secondary vapour, produced by the evaporator and use compressed vapour with high pressure as a primary vapour flow. Receiving of clean hot water by this method is made by low energy cost, because when the process of evaporation is started, there is no need to supply additional energy to maintenance the process.

Energy efficiency of MVR heat pump system is based on the values of two basic parameters: specific energy consumption for production of $1 \mathrm{~kg}$ condensate $(\mathrm{Wh} / \mathrm{kg})$ and actual coefficient of performance (-) $[1,2]$. In wastewater MVR heat pump systems the

* Corresponding author: slav_vul4ev@abv.bg 
difference between evaporation temperature of wastewater in separator and temperature of the compressed vapour is very small, which determines a high values of coefficient of performance of MVR heat pump systems (from 10 to 30) $[3,4,5]$.

In this study a relation between actual coefficient of performance and two significant factors - temperature of secondary vapour and compression ratio of water vapour in mechanical compressor of MVR heat pump system is received.

\section{Pilot MVR heat pump system}

For the purpose of the study a pilot MVR heat pump system for wastewater treatment is built. The installation is located in Plovdiv, Bulgaria, at laboratory of the University Of Food Technology - Plovdiv. Schematic diagram of MVR heat pump system is shown on Figure 1.

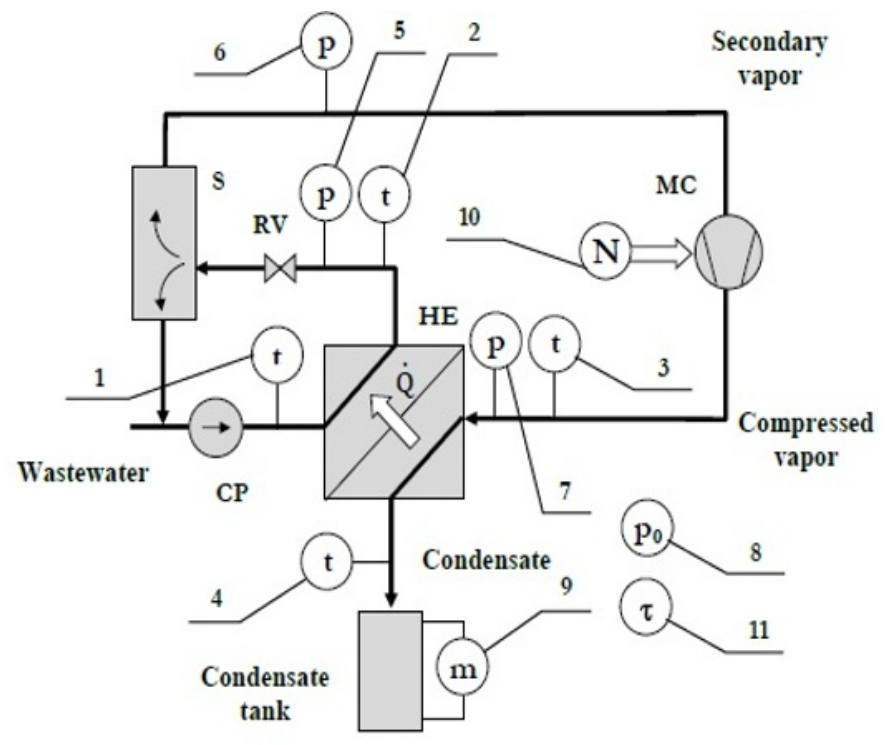

Fig. 1. Schematic diagram of mechanical vapour recompression heat pump system [6]

The wastewater goes to a plate heat exchanger HE, where it is heated by secondary vapour to a higher temperature. The temperature of wastewater at inlet of heat exchanger HE is measured with thermometer 1 . Since the circulation pump CP creates a certain pressure in the heat exchanger HE, wastewater is in the state of non-boiling liquid. The temperature of wastewater at outlet of heat exchanger $\mathrm{HE}$ is measured with thermometer 2 . The gauge pressure of wastewater at outlet of heat exchanger is measured with manometer 5. After leaving the heat exchanger $\mathrm{HE}$, the wastewater passes through a reducing valve $\mathrm{RV}$, which reduced wastewater pressure and when wastewater enters to the separator $\mathrm{S}$, it starts to evaporate. The secondary vapour enters in suction side of mechanical compressor $\mathrm{MC}$, which compresses them to a high pressure. The vacuum pressure of secondary vapour at outlet of separator $\mathrm{S}$ is measured with vacuum meter 6 . The compressed vapour at discharge side of mechanical compressor MC enters to the plate heat exchange HE, where delivers heat to wastewater. In heat exchanger HE compressed vapour turned to condensate is discharged to condensate tank 9. The temperature of compressed vapour at outlet of mechanical compressor $\mathrm{MC}$ is measured with thermometer 3 . The vacuum pressure of compressed vapour at outlet of mechanical compressor $\mathrm{MC}$ is measured with vacuum meter 7. The mass of condensate is measured by condensate tank 9 and electronic scale. 
The operation time of MVR heat pump system (time to collect condensate, produced on the system) is measured by chronometer 11 . The atmospheric pressure is measured by barometer 8 . The power consumption of electrical energy spent by mechanical compressor $\mathrm{MC}$ is measured by wattmeter 10 .

Measuring devices and measured parameters of MVR heat pump system are shown in Table 1.

Table 1. Measuring devices and measured parameters of pilot MVR heat pump system

\begin{tabular}{|c|c|c|c|c|}
\hline $\begin{array}{l}\text { Measuring } \\
\text { device }\end{array}$ & $\begin{array}{l}\text { Measured } \\
\text { parameter }\end{array}$ & Designation & $\begin{array}{l}\text { Precision } \\
\text { measuring }\end{array}$ & $\begin{array}{l}\text { Measuring } \\
\text { range }\end{array}$ \\
\hline $\begin{array}{c}\text { Thermometer } \\
1\end{array}$ & $\begin{array}{c}\text { Temperature of circulating water at } \\
\text { heat exchanger HE inlet }\end{array}$ & $\begin{array}{l}\mathrm{t}_{\mathrm{sv}}, \\
{ }^{\circ} \mathrm{C}\end{array}$ & $1.0^{\circ} \mathrm{C}$ & $\begin{array}{c}0-120 \\
{ }^{\circ} \mathrm{C}\end{array}$ \\
\hline $\begin{array}{l}\text { Thermometer } \\
2\end{array}$ & $\begin{array}{l}\text { Temperature of the circulating } \\
\text { water at heat exchanger HE outlet }\end{array}$ & $\frac{\mathrm{t}_{\text {out }},}{{ }^{\circ} \mathrm{C}}$ & $1.0^{\circ} \mathrm{C}$ & $\stackrel{0-120}{{ }^{\circ} \mathrm{C}}$ \\
\hline $\begin{array}{l}\text { Manometer } \\
\quad 5\end{array}$ & $\begin{array}{c}\text { Water pressure in heat exchanger } \\
\text { HE }\end{array}$ & $\begin{array}{l}\mathrm{p}_{\mathrm{HE}} \\
\mathrm{kPa}\end{array}$ & 0.1 bar & $\begin{array}{l}-1-3 \\
\text { bar }\end{array}$ \\
\hline $\begin{array}{l}\text { Vacuum meter } \\
6\end{array}$ & $\begin{array}{l}\text { Vacuum pressure of secondary } \\
\text { vapour in separator S /suction side } \\
\text { of mechanical compressor MC }\end{array}$ & $\begin{array}{l}\mathrm{p}_{\mathrm{v}, \mathrm{evap}} \\
\mathrm{kPa}\end{array}$ & $0.5 \mathrm{kPa}$ & $\begin{array}{c}0-100 \\
\mathrm{kPa}\end{array}$ \\
\hline $\begin{array}{l}\text { Vacuum meter } \\
7\end{array}$ & $\begin{array}{l}\text { Vacuum pressure of compressed } \\
\text { vapour/discharge side of } \\
\text { mechanical compressor MC }\end{array}$ & $\begin{array}{l}\mathrm{p}_{\mathrm{v}, \text { cond }} \\
\mathrm{kPa}\end{array}$ & $0.5 \mathrm{kPa}$ & $\begin{array}{c}0-100 \\
\mathrm{kPa}\end{array}$ \\
\hline $\begin{array}{l}\text { Barometer } \\
\quad 8\end{array}$ & Atmospheric pressure & $\begin{array}{l}\mathrm{p}_{0} \\
\mathrm{kPa}\end{array}$ & $1.0 \mathrm{mmHg}$ & $\begin{array}{l}740-780 \\
\mathrm{~mm} \mathrm{Hg}\end{array}$ \\
\hline $\begin{array}{l}\text { Water tank } \\
\quad 9\end{array}$ & Mass of condensate & $\begin{array}{l}\mathrm{m}, \\
\mathrm{kg}\end{array}$ & $10.0 \mathrm{~g}$ & $\begin{array}{c}0-10 \\
\mathrm{~kg}\end{array}$ \\
\hline $\begin{array}{c}\text { Chronometer } \\
11\end{array}$ & $\begin{array}{l}\text { Operation time of MVR } \\
\text { heat pump system }\end{array}$ & $\begin{array}{l}\tau, \\
\mathrm{s}\end{array}$ & $1 \mathrm{~s}$ & $\begin{array}{c}0-60 \\
\mathrm{~s}\end{array}$ \\
\hline $\begin{array}{l}\text { Wattmeter } \\
10\end{array}$ & $\begin{array}{l}\text { Power consumption of electrical } \\
\text { energy spent by mechanical } \\
\text { compressor MC }\end{array}$ & $\begin{array}{l}\mathrm{N}, \\
\mathrm{W}\end{array}$ & $10 \mathrm{~W}$ & $\begin{array}{l}0-999999.9 \\
\mathrm{kWh}\end{array}$ \\
\hline
\end{tabular}

A pilot MVR heat pump system performance is between 5.0 and $16.0 \mathrm{~kg} / \mathrm{h}$ evaporated water from intake wastewater flow. Absolute evaporating pressure in separator $\mathrm{S}$ has values from 15.5 to $25.0 \mathrm{kPa}$. Absolute pressure of compressed vapour at discharge side of mechanical compressor $\mathrm{MC}$ has values from 20 to $43 \mathrm{kPa}$. This difference in pressures provides difference between temperature of secondary vapour and temperature of compressed vapour from 5 to $13 \mathrm{~K}$. These pressures (at lack of physical-chemical temperature depression) correspond to saturation evaporation temperature between 55 and $67{ }^{\circ} \mathrm{C}$ and saturation condensation temperatures between 60 and $78^{\circ} \mathrm{C}$. There is also a temperature difference between 5 and $14 \mathrm{~K}$ of temperatures of wastewater in inlet and outlet of plate heat exchanger HE[13]. General appearance of MVR heat pump system is shown on Figure 2. 


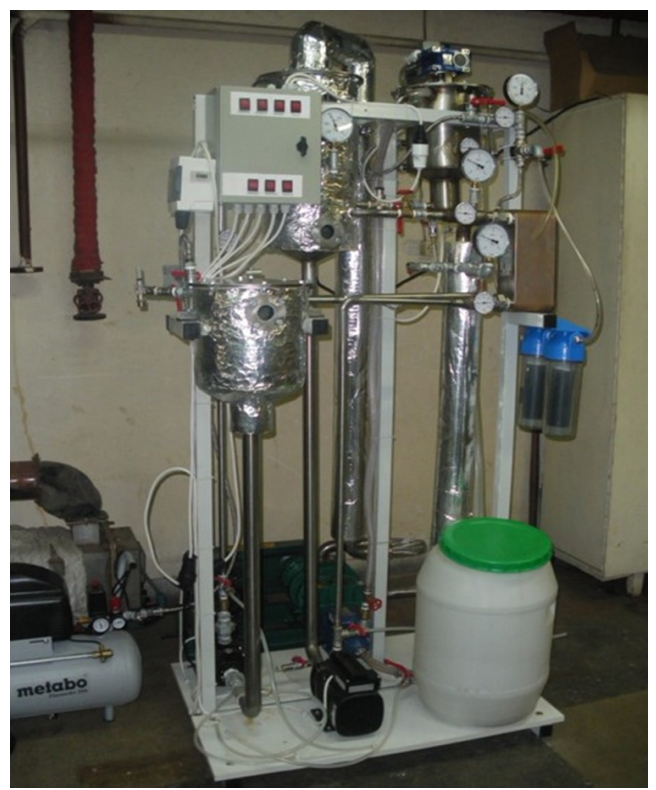

Fig. 2. General appearance of mechanical vapour recompression heat pump system [7]

\section{Analysis and discussion}

\subsection{Basic equation}

The mass flow rate of water circulating through the heat exchanger $m_{W}$ is determined by

the factory performance characteristic ( $V-\Delta$ p characteristic) of the circulator pump CP, according to the pressure $\Delta \mathrm{p}_{\mathrm{CP}}$ :

$$
\Delta p_{C P}=p_{H E}-p_{\text {evap }},
$$

where: - $\mathrm{p}_{\mathrm{HE}}-$ absolute pressure of wastewater in heat exchanger $\mathrm{HE}, \mathrm{kPa}$;

$\mathrm{p}_{\text {evap }}$ - absolute pressure of secondary vapour in separator $\mathrm{S}, \mathrm{kPa}$.

Heat flux exchanged in the heat exchanger $Q$ is determines by the equation of energy balance of wastewater flow rate through heat exchanger HE:

$$
\dot{Q}=\dot{m}_{W} c\left(t_{\text {out }}-t_{\text {evap }}\right)
$$

where: - $m_{W}$ is mass flow rate of wastewater circulating through the heat exchanger, $\mathrm{kg} / \mathrm{s}$; $\mathrm{c}$ - specific heat capacity of the wastewater, specified for wastewater average temperature, $\mathrm{kJ} /(\mathrm{kg} . \mathrm{K})$;

$\mathrm{t}_{\text {out }}$ - temperature of wastewater of outlet of heat exchanger $\mathrm{HE},{ }^{\circ} \mathrm{C}$;

$\mathrm{t}_{\text {evap }}$ - temperature of wastewater of inlet of heat exchanger HE, equal to the evaporation temperature of wastewater in separator $\mathrm{S},{ }^{\circ} \mathrm{C}$. 
A mass flow rate of vapour through the mechanical compressor $m_{K}$ can be calculated from the equation of the material balance. It is equal to the mass flow rate of the collected condensate:

$$
\dot{m}_{K}=\frac{m}{\tau}
$$

where: - $\mathrm{m}$ - total quantity of condensate collected in the condensate tank, $\mathrm{kg}$;

$\tau$ - operation time for collecting the condensate, $s$.

The process of compression of water vapour in mechanical compressor MC of MVR heat pump system is considered. It is a not isentropic process of compression of real gas - water vapour. The process of compression of water vapour occurs at low absolute pressure (between $15.5 \mathrm{kPa}$ and $43.0 \mathrm{kPa}$ ). The compressibility factor of water vapour is calculated by the equation:

$$
z=\frac{p V}{R T}
$$

where:- $\mathrm{z}$ - compressibility factor, -;

$\mathrm{p}$-absolute pressure of water vapour, $\mathrm{MPa}$;

$\mathrm{V}$-volume of water vapour, $\mathrm{m}^{3}$;

$\mathrm{R}$-individual gas constant of water vapour, $\mathrm{J} /(\mathrm{kg} . \mathrm{K})$;

$\mathrm{T}$-absolute temperature of water vapour, $\mathrm{K}$;

The value of compressibility factor in this case is between 0.993 and 0.996 , which is very close to 1 . In this case vapour can be considered as an ideal gas. Proximate theoretical process to the real process in MVR heat pump system is isentropic compression of ideal gas. In this process submitted specific flow work $l_{t}$ will match with the defined target function actual coefficient of performance of MVR heat pump system. This work for isentropic process of an ideal gas is calculated by the equation [8]:

$$
l_{t}=\frac{k}{k-1} R T_{\text {evap }}\left[1-\left(\frac{p_{\text {cond }}}{p_{\text {evap }}}\right)^{\frac{k-1}{k}}\right]
$$

where: $-1_{\mathrm{t}}-$ specific flow work, $\mathrm{J} / \mathrm{kg}$;

$\mathrm{k}-$ specific heat ratio,-;

$\mathrm{R}$-individual gas constant of water vapour, $\mathrm{J} /(\mathrm{kg} . \mathrm{K})$;

$\mathrm{T}_{\text {evap }}$ - absolute temperature of evaporation of wastewater, $\mathrm{K}$;

$\mathrm{p}_{\text {cond }}$ - absolute pressure of compressed vapour, $\mathrm{Pa}$.

$\mathrm{p}_{\text {evap }}$ - absolute pressure on secondary vapour in the separator $\mathrm{S}, \mathrm{Pa}$.

At lack of physical-chemical temperature depression the value of evaporation temperature of wastewater is equal to temperature of the secondary vapour $\left(t_{\text {evap }}=t_{s v}\right)$.

This relationship is accepted as a basis for mathematical model experiment by converting in form:

$$
l=\left(A_{1} t_{s v}+A_{2}\right) \sigma^{A_{3}}
$$

where: - 1 - actual coefficient of performance, -;

$\mathrm{t}_{\mathrm{sv}}$ - temperature of secondary vapour, ${ }^{\circ} \mathrm{C}$;

$\sigma$-compression ratio of water vapour in the mechanical compressor $\mathrm{MC},-$;

$\mathrm{A}_{1}, \mathrm{~A}_{2}, \mathrm{~A}_{3}$ - coefficients,-;

From the analysis of this relationship, the following important factors of the actual coefficient of performance 1 are defined: temperature of secondary water vapour $t_{\mathrm{sv}}$ and compression ratio of water vapour in the mechanical compressor MC $\sigma$. 
Compression ratio of mechanical compressor is calculated by the equation:

$$
\sigma=\frac{p_{\text {cond }}}{p_{\text {evap }}}
$$

where: $-\mathrm{p}_{\text {cond }}$ is absolute pressure of compressed vapour, $\mathrm{Pa}$;

$\mathrm{p}_{\text {evap }}$ - absolute pressure on secondary vapour in the separator $\mathrm{S}, \mathrm{Pa}$.

Guidelines for selecting the relevant factors in the objective function actual coefficient of performance $\mu$ gives dependence (8) for the theoretical one $\mu_{\mathrm{th}}[9,10]$ :

$$
\mu_{t h}=\frac{T_{c o n d}}{T_{\text {cond }}-T_{s v}}
$$

where: - $\mathrm{T}_{\text {cond }}$ - thermodynamic temperature of compressed vapour, $\mathrm{K}$;

$\mathrm{T}_{\mathrm{sv}}$ - thermodynamic temperature of secondary vapour, $\mathrm{K}$.

In this dependence temperatures of compressed and secondary vapour are identified as a saturation temperatures for pressures of compressed and secondary vapour by tables for water and water vapour.

A mathematical model that examined objective function is selected function analogous to (6):

$$
\mu=\left(A_{1} t_{s v}+A_{2}\right) \sigma^{A_{3}}
$$

Actual coefficient of performance $\mu$ is calculated by the equation [4],[5]:

$$
\mu=\frac{\dot{Q}}{|N|},
$$

where:- $\dot{Q}$ - heat flux exchanged in heat exchanger, $\mathrm{w}$;

$\mathrm{N}$ - power consumption of electrical energy by mechanical compressor MC of MVR heat pump system, $\mathrm{W}$.

\subsection{Results}

A different sample of industrial wastewater were researched: water from steam boiler blow down, water from CIP (cleaning in place) system of milk factory, water from refrigerant condenser blow down, water from washing vehicles and water from washing a catering equipment. This type of wastewater has low values of organic dry matter. In researched temperature interval no physical-chemical temperature depression was found. Therefore, it is assumed that the evaporation temperature of wastewater is equal to the temperature of the secondary vapour $\left(t_{\text {evap }}=t_{\text {sv }}\right)$. With a particular type of waste water, the pilot MVR heat pump system is started and introduced into an established operating mode, including stable maintenance of operating parameters and condensate generation. For a certain period of time the volume of generated condensate is collected and measured.

A classic experiment by two significant factors is conducted. The small number of factors $(n=2)$ allows the study to be carried out by classical multi-term experiment. A classic full plan of experiment including all recurring combinations of levels of factors is selected. The factors whose influence has been studied are defined: temperature of secondary water vapour in separator $\mathrm{S} \mathrm{t}_{\mathrm{sv}}$ and compression ratio of water vapour in the mechanical compressor $\mathrm{MC} \sigma$.

The scheme of the experiment is unbalanced with three levels of variation of the temperature of secondary water vapour in separator $\mathrm{t}_{\mathrm{sv}}-55^{\circ} \mathrm{C}, 60{ }^{\circ} \mathrm{C}, 65^{\circ} \mathrm{C}$ and five levels of varying of the compression ratio of water vapour in the mechanical compressor $\mathrm{MC}$ 
$\sigma-1.30,1.40,1.50,1.60$ and 1.70. Levels of variation of two significant factors are also determined by the specific design of pilot MVR heat pump system.

The results of experimental studies are shown in Table 2, Table 3 and Table 4.

Table 2. Experimental data - Study 1

\begin{tabular}{|c|c|c|c|c|c|c|c|c|}
\hline \multirow{2}{*}{$o$} & \multirow{2}{*}{$\mathrm{t}_{\mathrm{sv}}$} & $\sigma$ & $\Delta \mathrm{p}_{\mathrm{CP}}$ & $m_{W}$ & $\mathrm{t}_{\text {out }}$ & $\dot{Q}$ & $\mathrm{~N}$ & $\mu$ \\
\cline { 2 - 9 } & ${ }^{\circ} \mathrm{C}$ & - & $\mathrm{kPa}$ & $\mathrm{kg} / \mathrm{s}$ & ${ }^{\circ} \mathrm{C}$ & $\mathrm{W}$ & $\mathrm{W}$ & - \\
\hline 1 & 54.7 & 1.290 & 165.0 & 0.175 & 64.0 & 6846 & 680 & 10.07 \\
\hline 2 & 56.0 & 1.394 & 165.0 & 0.175 & 63.0 & 5148 & 700 & 7.35 \\
\hline 3 & 55.3 & 1.500 & 164.0 & 0.185 & 61.0 & 4390 & 730 & 6.01 \\
\hline 4 & 54.7 & 1.613 & 165.0 & 0.175 & 59.5 & 3540 & 750 & 4.72 \\
\hline 5 & 55.3 & 1.719 & 166.5 & 0.160 & 60.2 & 3254 & 840 & 3.87 \\
\hline 6 & 60.1 & 1.300 & 164.0 & 0.185 & 70.0 & 7685 & 670 & 11.47 \\
\hline 7 & 60.6 & 1.390 & 164.5 & 0.180 & 68.6 & 6017 & 700 & 8.60 \\
\hline 8 & 59.0 & 1.526 & 165.0 & 0.175 & 66.0 & 5145 & 800 & 6.43 \\
\hline 9 & 59.0 & 1.632 & 165.0 & 0.175 & 65.0 & 4410 & 820 & 5.38 \\
\hline 10 & 60.1 & 1.750 & 164.0 & 0.185 & 64.9 & 3725 & 880 & 4.23 \\
\hline 11 & 65.9 & 1.288 & 164.5 & 0.180 & 80.0 & 10681 & 720 & 14.83 \\
\hline 12 & 65.0 & 1.400 & 165.0 & 0.175 & 77.0 & 8823 & 760 & 11.61 \\
\hline 13 & 66.7 & 1.481 & 165.0 & 0.175 & 77.5 & 7926 & 800 & 9.91 \\
\hline 14 & 65.9 & 1.615 & 165.0 & 0.175 & 75.0 & 6711 & 900 & 7.46 \\
\hline 15 & 65.0 & 1.712 & 165.0 & 0.175 & 73.5 & 6252 & 1100 & 5.68 \\
\hline
\end{tabular}

Table 3. Experimental data - Study 2

\begin{tabular}{|c|c|c|c|c|c|c|c|c|}
\hline \multirow{2}{*}{$o$} & \multirow{2}{*}{$\mathrm{t}_{\mathrm{sv}}$} & $\sigma$ & $\Delta \mathrm{p}_{\mathrm{CP}}$ & $m_{W}$ & $\mathrm{t}_{\text {out }}$ & $\dot{Q}$ & $\mathrm{~N}$ & $\mu$ \\
\cline { 2 - 9 } & ${ }^{\circ} \mathrm{C}$ & - & $\mathrm{kPa}$ & $\mathrm{kg} / \mathrm{s}$ & ${ }^{\circ} \mathrm{C}$ & $\mathrm{W}$ & $\mathrm{W}$ & - \\
\hline 1 & 54.7 & 1.290 & 165.0 & 0.175 & 63.7 & 6626 & 680 & 9.74 \\
\hline 2 & 56.0 & 1.394 & 164.0 & 0.185 & 62.5 & 5052 & 700 & 7.22 \\
\hline 3 & 55.3 & 1.500 & 164.0 & 0.185 & 61.0 & 4390 & 730 & 6.01 \\
\hline 4 & 54.7 & 1.613 & 165.0 & 0.175 & 60.0 & 3907 & 820 & 4.77 \\
\hline 5 & 55.3 & 1.719 & 166.5 & 0.160 & 60.0 & 3120 & 840 & 3.71 \\
\hline 6 & 60.1 & 1.300 & 164.0 & 0.185 & 70.2 & 7840 & 660 & 11.88 \\
\hline 7 & 60.6 & 1.390 & 164.5 & 0.180 & 69.0 & 6320 & 700 & 9.03 \\
\hline 8 & 59.0 & 1.526 & 165.0 & 0.175 & 66.4 & 5439 & 800 & 6.80 \\
\hline 9 & 59.0 & 1.632 & 164.0 & 0.185 & 65.4 & 4971 & 830 & 5.99 \\
\hline 10 & 60.1 & 1.750 & 164.0 & 0.185 & 64.8 & 3648 & 850 & 4.29 \\
\hline 11 & 65.9 & 1.288 & 165.5 & 0.170 & 81.3 & 11013 & 710 & 15.51 \\
\hline 12 & 65.0 & 1.400 & 165.0 & 0.175 & 78.0 & 9558 & 750 & 12.74 \\
\hline 13 & 66.7 & 1.481 & 164.0 & 0.185 & 77.5 & 8377 & 800 & 10.47 \\
\hline 14 & 65.9 & 1.615 & 165.0 & 0.175 & 75.5 & 7079 & 910 & 7.78 \\
\hline 15 & 65.0 & 1.712 & 165.0 & 0.175 & 74.0 & 6619 & 1080 & 6.13 \\
\hline
\end{tabular}


Table 4. Experimental data - Study 3

\begin{tabular}{|c|c|c|c|c|c|c|c|c|}
\hline \multirow{2}{*}{ o } & $\mathrm{t}_{\mathrm{sv}}$ & $\sigma$ & $\Delta \mathrm{p}_{\mathrm{CP}}$ & $m_{W}$ & $\mathrm{t}_{\text {out }}$ & $\dot{Q}$ & $\mathrm{~N}$ & $\mu$ \\
\cline { 2 - 9 } & ${ }^{\circ} \mathrm{C}$ & - & $\mathrm{kPa}$ & $\mathrm{kg} / \mathrm{s}$ & ${ }^{\circ} \mathrm{C}$ & $\mathrm{W}$ & $\mathrm{W}$ & - \\
\hline 1 & 54.7 & 1.290 & 165.0 & 0.175 & 64.0 & 6846 & 690 & 9.92 \\
\hline 2 & 56.0 & 1.394 & 164.0 & 0.185 & 63.0 & 5440 & 710 & 7.66 \\
\hline 3 & 55.3 & 1.500 & 165.0 & 0.175 & 61.0 & 4154 & 730 & 5.69 \\
\hline 4 & 54.7 & 1.613 & 165.0 & 0.175 & 59.8 & 3760 & 810 & 4.64 \\
\hline 5 & 55.3 & 1.719 & 166.5 & 0.160 & 60.3 & 3322 & 830 & 4.00 \\
\hline 6 & 60.1 & 1.300 & 164.0 & 0.185 & 69.6 & 7374 & 670 & 11.01 \\
\hline 7 & 60.6 & 1.390 & 164.5 & 0.180 & 68.5 & 5942 & 660 & 9.00 \\
\hline 8 & 59.0 & 1.526 & 165.0 & 0.175 & 66.0 & 5145 & 760 & 6.77 \\
\hline 9 & 59.0 & 1.632 & 165.0 & 0.175 & 65.1 & 4484 & 830 & 5.40 \\
\hline 10 & 60.1 & 1.750 & 165.0 & 0.175 & 65.0 & 3598 & 860 & 4.18 \\
\hline 11 & 65.9 & 1.288 & 165.5 & 0.170 & 81.7 & 11298 & 710 & 15.91 \\
\hline 12 & 65.0 & 1.400 & 165.0 & 0.175 & 78.0 & 9558 & 750 & 12.74 \\
\hline 13 & 66.7 & 1.481 & 164.0 & 0.185 & 78.0 & 8765 & 820 & 10.69 \\
\hline 14 & 65.9 & 1.615 & 165.0 & 0.175 & 75.0 & 6711 & 880 & 7.63 \\
\hline 15 & 65.0 & 1.712 & 165.0 & 0.175 & 74.0 & 6619 & 1060 & 6.24 \\
\hline
\end{tabular}

Statistical processing of experimental data is made. This includes: checking for homogeneity of variances, check significance of odds betting in the regression equations and check the adequacy of the resulting equations was carried out [11]. A summary experimental data from studies 1,2 and 3 are shown in Table $5 . X_{1}$ and $X_{2}$ are significant factors - temperature of secondary water vapour in separator $\mathrm{S}_{\mathrm{sv}}$ and compression ratio of water vapour in the mechanical compressor $M C \sigma . Y_{2,1}, Y_{2,2}, Y_{2,3}$ are the results of objective function actual coefficient of performance of MVR heat pump, measured three times and $\mathrm{Y}_{2}$ is respective arithmetical mean value of actual coefficient of performance $\mu$ of MVR heat pump.

Table 5. Summary experimental data - Study 1,2 and 3

\begin{tabular}{|c|c|c|c|c|c|c|}
\hline \multirow{2}{*}{$№$} & $\mathrm{X}_{1}$ & $\mathrm{X}_{2}$ & $\mathrm{Y}_{2,1}$ & $\mathrm{Y}_{2,2}$ & $\mathrm{Y}_{2,3}$ & $\mathrm{Y}_{2}$ \\
\cline { 2 - 7 } & ${ }^{\circ} \mathrm{C}$ & - & - & - & - & - \\
\hline 1 & 54.7 & 1.290 & 10.07 & 9.74 & 9.92 & 9.91 \\
\hline 2 & 56.0 & 1.394 & 7.35 & 7.22 & 7.66 & 7.41 \\
\hline 3 & 55.3 & 1.500 & 6.01 & 6.01 & 5.69 & 5.90 \\
\hline 4 & 54.7 & 1.613 & 4.72 & 4.77 & 4.64 & 4.71 \\
\hline 5 & 55.3 & 1.719 & 3.87 & 3.71 & 4.00 & 3.86 \\
\hline 6 & 60.1 & 1.300 & 11.47 & 11.88 & 11.01 & 11.45 \\
\hline 7 & 60.6 & 1.390 & 8.60 & 9.03 & 9.00 & 8.88 \\
\hline 8 & 59.0 & 1.526 & 6.43 & 6.80 & 6.77 & 6.67 \\
\hline 9 & 59.0 & 1.632 & 5.38 & 5.99 & 5.40 & 5.59 \\
\hline 10 & 60.1 & 1.750 & 4.23 & 4.29 & 4.18 & 4.23 \\
\hline 11 & 65.9 & 1.288 & 14.83 & 15.51 & 15.91 & 15.42 \\
\hline 12 & 65.0 & 1.400 & 11.61 & 12.74 & 12.74 & 12.36 \\
\hline 13 & 66.7 & 1.481 & 9.91 & 10.47 & 10.69 & 10.36 \\
\hline 14 & 65.9 & 1.615 & 7.46 & 7.78 & 7.63 & 7.62 \\
\hline 15 & 65.0 & 1.712 & 5.68 & 6.13 & 6.24 & 6.02 \\
\hline
\end{tabular}

Objective function actual coefficient of performance obtained equation is as follows: 


$$
Y_{2}=\left(1.411 . X_{1}-56.47\right) X_{2}^{-3.27}
$$

Regression equation for actual coefficient of performance is obtained by replacing parameters $Y_{2}=\mu, X_{1}=t_{s v}$ and $X_{2}=\sigma$ :

$$
\mu=\left(1.411 t_{s v}-56.47\right) \sigma^{-3.27}
$$

In Figure 3 a correlation between objective function actual coefficient of performance and two significant factors: compression ratio and temperature of secondary vapour in separator as a parameter is shown.

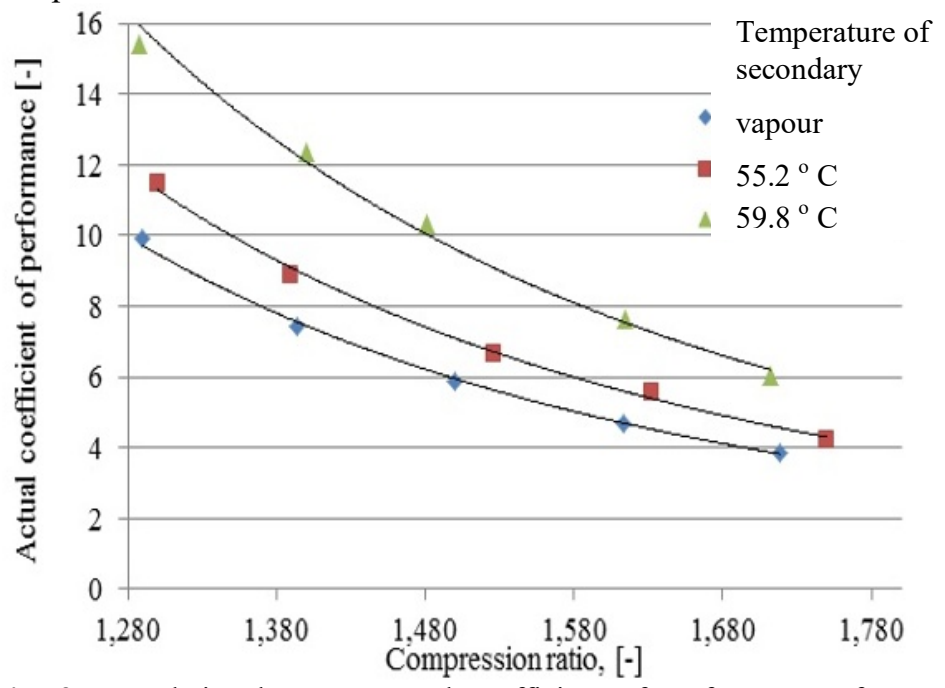

Fig. 3. Correlation between actual coefficient of performance of MVR heat pump system and two independent factors: compression ratio and temperature secondary vapour

In Table 6 a comparison of the values of theoretical $\mu_{\text {th }}$ and actual coefficient of performance of MVR heat pump system $\mu$ are given. The values of theoretical coefficient of performance of MVR heat pump system $\mu_{\text {th }}$ are calculated by equation (8).

Table 6. Comparison of the values of the theoretical and actual coefficient of performance of MVR heat pump system

\begin{tabular}{|c|c|c|c|c|}
\hline $\mathrm{t}_{\mathrm{sv}}$ & $\sigma$ & $\mu_{\mathrm{th}}$ & $\mu$ & $\mu_{\mathrm{th}} / \mu$ \\
\hline${ }^{\circ} \mathrm{C}$ & - & - & - & - \\
\hline 54.7 & 1.290 & 61.5 & 9.91 & 6.21 \\
\hline 56.0 & 1.394 & 47.0 & 7.41 & 6.34 \\
\hline 55.3 & 1.500 & 38.6 & 5.90 & 6.54 \\
\hline 54.7 & 1.613 & 32.8 & 4.71 & 6.96 \\
\hline 55.3 & 1.719 & 28.9 & 3.86 & 7.49 \\
\hline 60.1 & 1.300 & 58.8 & 11.45 & 5.14 \\
\hline 60.6 & 1.390 & 46.8 & 8.88 & 5.27 \\
\hline 59.0 & 1.526 & 36.6 & 6.67 & 5.49 \\
\hline 59.0 & 1.632 & 31.6 & 5.59 & 5.65 \\
\hline 60.1 & 1.750 & 27.5 & 4.23 & 6.50 \\
\hline 65.9 & 1.288 & 59.5 & 15.42 & 3.86 \\
\hline 65.0 & 1.400 & 44.9 & 12.36 & 3.63 \\
\hline 66.7 & 1.481 & 38.0 & 10.36 & 3.67 \\
\hline 65.9 & 1.615 & 31.2 & 7.62 & 4.09 \\
\hline 65.0 & 1.712 & 27.7 & 6.02 & 4.60 \\
\hline
\end{tabular}




\section{Conclusions}

The analysis of graphic dependencies (Fig.3) and equation (12) show that actual coefficient of performance in pilot MVR heat pump system $\mu$ highly depends of the compression ratio of water vapour in mechanical compressor $M C \sigma$. The relation between these two variables in the study area is inverse speed dependence with negative exponent value $A_{3}=-3.27$.

Less dependence on actual coefficient of performance $\mu$ proves temperature of secondary vapour $t_{\mathrm{sv}}$. It is linear proportional correlation between actual coefficient of performance $\mu$ and temperature of secondary vapour $\mathrm{t}_{\mathrm{sv}}$ because of positive value of coefficient $\mathrm{A}_{1}=1.411$. In researched interval values of actual coefficient of performance of MVR heat pump system $\mu$ are between 3.86 and 15.42 , and the theoretical one $\mu_{\text {th }}$ - from 3.63 to 7.49 times greater. As a result, it can conclude that pilot MVR heat pump system, in order to operate with high values of the actual coefficient of performance $\mu$ should be working to high values of temperatures of secondary vapour $t_{\mathrm{sv}}$ and low values of compression ratio of water vapour in mechanical compressor $\sigma$.

\section{References}

1. H. Aybar, Desalination 142 (2), 181-186 (2002)

2. H. Ettouney, Desalination 190, 1-15 (2006)

3. D. De Waal, Feasibility Study of Heat Pumps for Waste Heat Recovery in Industry (Master of Science Thesis, 2012)

4. W. Pang, L. Wenju, P. Qilin, L. Wenye, D. Qunte, Y. Luwei, Z. Zhentao. Presented at AIP Conf. Proc. 1573, 1122-1128 (2014)

5. C.Tuan., Y. Cheng, Y. Yeh, L. Hsu, T. Chen. Sustain. Environ.Res., 23(2), 129-139 (2013).

6. S. Valchev, Application of a heat pump system for industrial waste water purification. (Master of Science Thesis, University of Food Technology 2015).

7. S. Valchev, N. Nenov, Heat Engineering, 2, $72-75$ (2014).

8. G. Kimenov, Thermal Engineering, (In Bulgarian - State Publishing House "Technique", Sofia, 1977).

9. S. Dichev, Refrigeration machines. (In Bulgarian - Academic Publishing of VIHVP Plovdiv, 2002)

10. V. Eder, F. Moser. Thermal pumps, (In Bulgarian - State Publishing House "Technique", Sofia, 1984)

11. G. Raichkov, Measurements and appliances in heat engineering, (In Bulgarian Academic Publishing of University of food technology - Plovdiv, 2001) 